\title{
Anticonvulsant drugs alter plasma tryptophan concentrations in epileptic patients: implications for antiepileptic action and mental function
}

\author{
JA PRATT, P JENNER, AL JOHNSON, SD SHORVON, EH REYNOLDS
}

From the University Department of Neurology, Institute of Psychiatry and King's College Hospital Medical School, London and the MRC Biostatistics Unit, MRC Centre, Hills Road, Cambridge, UK

SUMMARY In epileptic patients carbamazepine and diphenylhydantoin have opposite effects on whole and free plasma tryptophan concentrations, the former elevating and the latter depressing them. It is unlikely that these observations relate to the similar anti-epileptic properties of these two drugs but they may relate to their different effects on mental function and mood.

In animals several anticonvulsant drugs increase serotonin (5HT) concentrations due to a decrease in 5HT turnover.' There has been much interest in whether this observation relates to the therapeutic or toxic effects of the drugs. ${ }^{12}$ However, studies of the effects of anticonvulsants on the concentration of 5-hydroxyindoleacetic acid (5HIAA), a product of 5HT metabolism, in cerebrospinal fluid from epileptic patients have produced conflicting results. ${ }^{23}$ Since free plasma tryptophan concentrations may influence brain 5HT turnover ${ }^{4}$ we have investigated the influence of anticonvulsants, in particular carbamazepine and diphenylhydantoin on whole, bound and free plasma tryptophan concentrations in chronic epileptic patients and in newly diagnosed epileptic patients before and after the introduction of single drug therapy.

\section{Patients and methods}

The epileptic patients were attending the neurological out-patient department of King's College Hospital, London. They included (1) 24 untreated new referrals (median age 25 years, range 12 to 61 ), 14 of whom had tonic-clonic seizures, four partial and six mixed tonic-clonic and partial seizures; (2) 56 chronic patients (median age 25 years, range 17 to 75 ), 30 of whom had tonic-clonic seizures, 17 partial and nine mixed tonic-clonic and partial seizures

Address for reprint requests: Dr EH Reynolds, Department of Neurology, King's College Hospital, Denmark Hill, London SE5.

Received 30 September 1983 and in revised form 3 May 1984. Accepted 5 May 1984 treated with a single anticonvulsant drug (carbamazepine for 14 patients; diphenylhydantoin for 35 , and phenobarbitone for seven patients). A control group consisted of 33 normal volunteers from the staff of King's College Hospital (median age 26 years, range 16 to 62 ). In 10 new referrals tryptophan concentrations were re-examined between 2 weeks and 23 months after the introduction of carbamazepine (400-800 $\mathrm{mg}$ daily) in seven and diphenylhydantoin (200-300 $\mathrm{mg}$ daily) in three.

At each out-patient clinic attendance $20 \mathrm{ml}$ of venous blood was taken for analysis. No dietary or fluid restrictions were imposed on the subjects. Whole and free plasma tryptophan were measured by the method of Eccleston; ${ }^{5}$ bound plasma tryptophan was estimated by subtraction of free from whole plasma tryptophan. Plasma concentrations of carbamazepine were measured by the gas chromatographic technique of Toseland et al, ${ }^{6}$ diphenylhydantoin and phenobarbitone by the technique of Kupferburg. ${ }^{7}$

\section{Results}

Table 1 summarises the plasma tryptophan concentrations in epileptic patients on different drugs, in untreated epileptics and in normal controls. Untreated epileptic patients had slightly lower whole and bound plasma tryptophan levels than normal volunteers. In patients on drug therapy a striking finding is that carbamazepine is associated with a significant elevation of whole, bound and free plasma tryptophan in comparison with all the other groups. The bound-to-free plasma tryptophan ratio also fell significantly with carbamazepine in comparison with all other groups. By contrast diphenylhydantoin is associated with a significant fall in whole, bound and free plasma tryptophan and 
Table 1 Plasma tryptophan concentrations (95\% confidence limits) in epileptic patients sub-divided by drug therapy, untreated epileptics and normal volunteers

\begin{tabular}{|c|c|c|c|c|c|}
\hline Group & $\begin{array}{l}\text { Clinic visits } \\
\text { (patients) }\end{array}$ & $\begin{array}{l}\text { Whole plasma } \\
\text { tryptophan }(\mu \mathrm{g} / \mathrm{ml})\end{array}$ & $\begin{array}{l}\text { Bound plasma } \\
\text { tryptophan }(\mu \mathrm{g} / \mathrm{ml})\end{array}$ & $\begin{array}{l}\text { Free plasma } \\
\text { tryptophan }(\mu \mathrm{g} / \mathrm{ml})\end{array}$ & $\begin{array}{l}\text { Bound/free } \\
\text { tryptophan ratio }\end{array}$ \\
\hline \multicolumn{6}{|l|}{ Epileptics } \\
\hline
\end{tabular}

Plasma tryptophan concentrations and bound/free tryptophan ratio were transformed logarithmically and analysed using a nested three-factor analysis of variance (clinic visit within patients within "drug" groups). Comparisons between means were made using the least significant difference (based on the mean square between patients within "drug" groups; $\mathrm{df}=108$. Figures are antilog (mean) (and antilog ( $95 \%$ confidence limits)) of transformed data. *All comparisons with carbamazepine group are significant $(p<0.001)$ except with bound plasma tryptophan for phenobarbitone group $(\mathrm{p}<0.005)$ and normal volunteers $(\mathrm{p}<0.025)$; other comparisons with normal volunteers tp $<0.05 ;$; $<0.025 ; \S p<0.001$.

phenobarbitone associated with a significant fall in free plasma tryptophan, in comparison with normal volunteers. For diphenylhydantoin and phenobarbitone similar trends were seen in comparison with untreated epileptic patients.

Table 2 relates plasma tryptophan concentrations to plasma concentrations of carbamazepine in patients treated with this drug. For car bamazepine whole, bound and free plasma tryptophan concentrations rise with increasing drug concentration. For diphenylhydantoin there is little change in tryptophan concentrations (except for a slight decline in free tryptophan) with increasing drug concentration (data not shown).

These results are supported by separate regression analyses of plasma tryptophan concentrations on drug plasma concentrations in patients treated with carbamazepine and diphenylhydantoin (data not shown). Total and free plasma concentrations increase with drug concentrations for carbamazepine; they show little change (regression coefficients negative but not significant at $\mathrm{p}=0.05$ ) for diphenylhydantoin.

Further support was obtained by an analysis of tryptophan concentrations in the 10 untreated epileptics who were subsequently re-examined on drug therapy. Total plasma tryptophan concentrations increased in all seven patients after the introduction of carbamazepine (paired $t$ test: $t=3 \cdot 35$, $\mathrm{df}=6, \mathrm{p}<0.05$ ) and decreased (though not significantly) in all three patients after the introduction of diphenylhydantoin; the difference between the changes in the two drug groups was highly significant $(F=11 \cdot 9, \mathrm{df}=1,8, \mathrm{p}<0.001)$. Both free and bound plasma tryptophan also increased in the patients given carbamazepine and decreased in those given diphenylhydantoin though these changes were not statistically significant at $\mathbf{p}=0 \cdot 05$.

\section{Discussion}

We have found that carbamazepine and diphenylhydantoin have opposite effects on whole and free plasma tryptophan concentrations, the former elevating and the latter depressing them. In a small sample the effect of phenobarbitone was similar to that of diphenylhydantoin. The mechanisms by which carbamazepine and diphenylhydantoin produce different alterations in plasma tryptophan concentrations are unknown. Carbamazepine is structurally related to the tricyclic anti-depressants and it has been shown recently that the latter inhibit

Table 2 Plasma tryptophan concentrations (95\% confidence limits) in epileptic patients treated with carbamazepine sub-divided by plasma drug concentration

\begin{tabular}{|c|c|c|c|c|c|}
\hline $\begin{array}{l}\text { Plasma drug } \\
\text { concentration }\end{array}$ & $\begin{array}{l}\text { Clinic visits } \\
\text { (patients) }\end{array}$ & $\begin{array}{l}\text { Whole plasma } \\
\text { tryptophan }(\mu \mathrm{g} / \mathrm{ml})\end{array}$ & $\begin{array}{l}\text { Bound plasma } \\
\text { tryptophan }(\mu \mathrm{g} / \mathrm{ml})\end{array}$ & $\begin{array}{l}\text { Free plasma } \\
\text { tryptophan }(\mu \mathrm{g} / \mathrm{ml})\end{array}$ & $\begin{array}{l}\text { Bound/free } \\
\text { tryptophan ratio }\end{array}$ \\
\hline $\begin{array}{c}\text { Subtherapeutic } \\
(<5 \mu \mathrm{ml})\end{array}$ & $9(9)$ & $11 \cdot 93+(10 \cdot 52,13 \cdot 52)$ & $9 \cdot 39(8 \cdot 25,10 \cdot 69)$ & $2 \cdot 48 \dagger(2.01,3.07)$ & $3.78(3.09,4.63)$ \\
\hline $\begin{array}{l}\text { Therapeutic } \\
(5-10 \mu \mathrm{g} / \mathrm{ml})\end{array}$ & $15(12)$ & $12 \cdot 40^{*}(11 \cdot 25,13 \cdot 66)$ & $9.69(8.76,10 \cdot 71)$ & $2 \cdot 61 \dagger(2 \cdot 21,3 \cdot 07)$ & $3 \cdot 72(3 \cdot 18,4 \cdot 34)$ \\
\hline $\begin{array}{l}\text { Toxic } \\
(>10 \mu \mathrm{g} / \mathrm{ml})\end{array}$ & $4(4)$ & $15 \cdot 54(12 \cdot 88,18 \cdot 76)$ & $11 \cdot 75(9 \cdot 68,14 \cdot 27)$ & $3 \cdot 74(2 \cdot 71,5 \cdot 14)$ & $3 \cdot 15(2 \cdot 33,4 \cdot 26)$ \\
\hline
\end{tabular}

Plasma tryptophan concentrations and bound/free tryptophan ratio were transformed logarithmically and analysed using a crossed two-factor analysis of variance (drug (carbamazepine/diphenylhydantoin) and drug concentration (subtherapeutic/therapeutic/toxic). There is a significant $(p<0.05)$ interaction between the two factors for whole and free plasma tryptophan. Comparisons between means were made using the least significant difference $(\mathrm{df}=75)$. Figures are antilog (mean) (and antilog $(95 \%$ confidence limits $)$ ) of transformed data. Significance of comparisons with toxic drug concentration group: ${ }^{*} p<0.05 ; \mathrm{p}<0.025$. 
liver tryptophan pyrrolase probably as a result of the prevention of conjugation of the apoenzyme with its cofactor haem. ${ }^{8}$ The possibility that carbamazepine has a similar effect requires investigation. The decrease in bound plasma tryptophan associated with diphenylhydantoin might reflect the high degree of protein binding of this drug causing displacement of the amino acid from its albumin binding site. ${ }^{9}$ Indeed, diphenylhydantoin and phenobarbitone competitively inhibit the binding of L-tryptophan onto human serum albumin in vitro. ${ }^{10}$ Another possibility is that both diphenylhydantoin and phenobarbitone enhance the activity of tryptophan pyrrolase by enzyme induction. ${ }^{9}$ However, carbamazepine is also a potent enzyme inducer, but has the reverse effects on plasma tryptophan concentrations.

Clinical studies suggest that there is little difference in the anti-epileptic efficacy of carbamazepine and diphenylhydantoin." It is therefore unlikely that the opposite effects of these two drugs on plasma tryptophan concentrations can be related to the anticonvulsant action of either drug. However, there is considerable evidence that the two drugs have different chronic effects on mental function. An encephalopathy has been reported with diphenylhydantoin (and phenobarbitone) but not with carbamazepine. ${ }^{12} 13$ In comparative studies of the two drugs in normal volunteers, ${ }^{14}$ chronic epileptic patients ${ }^{15}$ and new referrals with epilepsy, ${ }^{16}$ tests of psychomotor performance, attention, memory and mood have consistently favoured carbamazepine. Indeed, it has been claimed that carbamazepine has positive psychotropic effects with a beneficial influence on both mania and depression. ${ }^{17}$ In view of the evidence of a relationship between central serotonergic function and mood $^{18}$ we suggest that the different effects of carbamazepine and diphenylhydantoin on tryptophan concentrations which we have observed may be related to the different influence of the two drugs on mental function.

\section{References}

' Pratt JA, Jenner P, Marsden CD. Benzodiazepines, anticonvulsants, epilepsy and myoclonus. In: Morselli PL, Lloyd KG, Loscher W, Meldrum B, Reynolds EH, eds. Neurotransmitters, Seizures and Epilepsy. New York: Raven Press, 1981:227-38.

${ }^{2}$ Chadwick D, Jenner P, Reynolds EH. Serotonin metabolism in human epilepsy: the influence of anticonvulsant drugs. Ann Neurol 1977;1:218-24.
${ }^{3}$ Young SN, Gauthier S, Anderson GM, Purdy WC. Tryptophan, 5-hydroxyindoleacetic acid and indoleacetic acid in human cerebrospinal fluid: interrelationships and the influence of age, sex, epilepsy and anticonvulsant drugs. J Neurol Neurosurg Psychiatry 1980; 43: $438-45$.

${ }^{4}$ Curzon G. Relationships between plasma, CSF and brain tryptophan. J Neural Transmission, Suppl.15. 1979:81-92.

${ }^{5}$ Eccleston EG. A method for the estimation of free and total acid-soluble plasma tryptophan using an ultrafiltration technique. Clin Chim Acta 1973; 48:269-72.

- Toseland P, Grove J, Berry D. An isothermal GLC determination of the plasma levels of carbamazepine, diphenylhydantoin, phenobarbitone and primidone. Clin Chem Acta 1972;38:321-8.

${ }^{7}$ Kupferburg HJ. Quantitative estimation of diphenylhydantoin, primidone and phenobarbital by gas-liquid chromatography. Clin Chim Acta 1970;29:283-8.

${ }^{8}$ Badaway AA-B, Evans M. Inhibition of rat liver tryptophan pyrrolase activity and elevation of brain tryptophan concentration by administration of antidepressants. Biochem Pharmac 1981;30:1211-6.

9 Richens A. The Drug Treatment of Epilepsy. London: Henry Kimpton, 1976.

${ }^{10}$ Muller WE, Wollert U. Influence of various drugs on the binding of L-tryptophan to human serum albumin. Res Commun Chem Pathol Pharmacol 1975;10: 565-8.

"Reynolds EH. Serum levels of anticonvulsant drugs: interpretation and clinical value. Pharmacol Ther 1980;8:217-35.

12 Trimble M, Reynolds EH. Anticonvulsant drugs and mental symptoms. A review. Psychol Med 1976; 6:169-78.

${ }^{13}$ Reynolds EH. Biological factors in psychological disorders associated with epilepsy. In: Reynolds EH, Trimble MR, eds. Epilepsy and Psychiatry. Edinburgh: Churchill Livingstone, 1981:264-90.

${ }_{14}$ Trimble MR, Thompson PJ, Huppert F. Anticonvulsant drugs and cognitive abilities. In: Canger R, Angeleri F, Penry JK, eds. Advances in Epileptology. New York: Raven Press, 1980:199-204.

is Dodrill CB, Troupin AS. Psychotropic effects of carbamazepine in epilepsy. A double-blind comparison with phenytoin. Neurology (Minneap) 1977;27: 1023-8.

${ }^{16}$ Andrewes D, Tomlinson L, Elwes RDC, Reynolds EH. The influence of carbamazepine and phenytoin on memory and other aspects of cognitive function in new referrals with epilepsy. Communication to Memory Symposium, Gothenburg, 1983. Act Neurol Scand 1984;23: 23-30.

17 Post RM. Use of the anticonvulsant carbamazepine in primary and secondary affective illness: clinical and theoretical implications. Psychol Med 1982;12:701-4.

${ }^{18}$ van Praag HM. Neurotransmitters and CNS disease. Depression. Lancet 1982;ii:1259-64. 